\title{
HABITABILIDAD DE EDIFICACIONES Y RANKING DE DISCRIMINACIÓN BASADO EN SEGURIDAD Y SUSTENTABILIDAD FRENTE A EVENTUALES DESASTRES ESTUDIO DE CASO: VIVIENDAS DE MADERA
}

\author{
Rose Marie Garay ${ }^{1,2, *}$, Ricardo Tapia ${ }^{3,2}$, Miguel Castillo ${ }^{1}$, Oscar Fernández ${ }^{1}$ y Javiera Vergara ${ }^{1}$
}

\section{RESUMEN}

Toda vivienda debiese cumplir con estándares de seguridad, confort y durabilidad, aún más cuando debido al cambio climático los desastres tienden a ocurrir con mayor frecuencia. En Chile, los estándares de construcción se encuentran en la Ordenanza General de Urbanismo y Construcción (OGUC), cuya actualización incluirá elementos de gestión de riesgo para disminuir la vulnerabilidad. En este estudio, se evaluaron estándares mecánicos, térmicos, de aislación térmica y al fuego en 5 zonas térmicas. Esta información permitió la creación de manuales de construcción, instalación y especificaciones técnicas, y un proyecto de ley que regula los estándares de viviendas de emergencia y asentamientos transitorios. Esta experiencia permitió un análisis crítico del cumplimiento de estándares para viviendas sociales y edificaciones en madera, los que no consideraban, por ejemplo, opacidad y toxicidad del humo, aislantes térmicos y acústicos, resistencia al fuego, persevantes menos dañinos o recubrimientos sustentables. La existencia de disposiciones normativas en la ordenanza (OGUC) no implica que en la practica se cumplan los estándares de eficiencia energética, resistencia sísmica y al fuego simultáneamente en viviendas que además, en muchos casos, no cuentan con recepción final de obra. Estos análisis de discriminación multi-criterio ayudarán a la toma decisiones de diseño en construcción en madera.

\section{PALABRAS CLAVE}

Estándares de construcción de viviendas, Protección de la Madera, Resistencia al Fuego

\section{BUILDING HABITABILITY AND RANKING OF DISCRIMINATION BASED ON SAFETY AND SUSTAINABILITY TO DISASTERS. CASE STUDY: WOODEN HOUSES}

\section{ABSTRACT}

Every housing should fulfill safety, comfort and durability standards, even more when due to climate change disasters occur more often than ever. In Chile, construction standards can be found in the General Urban Planning and Construction Ordinance (OGUC), whose update will include elements for risk management in order to decrease vulnerability. In this study, thermal, mechanic, fire resistant and acoustic isolation standards where evaluated in 5 thermic zones. This information allowed the creation of manufacturing, installation, technical specification manuals, and a bill that regulates emergency housing and transient settlements standards. This experience allowed a critical analysis of the compliance with standards for social housing and wood building, which does not account, for example, for smoke opacity and toxicity, thermal-acoustic insulators and fire resistance: less harmful preservatives or coatings with sustainability in mind. The existence of the ordinance (OGUC) does not imply compliance of energy efficiency, seismic and fire resistance standards simultaneously in practice, as many housing projects do not consider a final reception of work. Multi-criteria discrimination analyzes may help to make design decisions in wood constructions.

\section{KEYWORDS}

Housing construction standards, Wood Protection, Buildings Fire resistance

1. Facultad de Ciencias

Forestales y de la

Conservación de la

Naturaleza, Universidad de Chile, Chile.

2. Programa de Reducción de Riesgos y Desastres CITRID, Universidad de Chile, Chile.

3. Instituto de la Vivienda INVI, Universidad de Chile, Chile.

*Autor de correspondencia: rgaray@uchile.cl

\section{RECIBIDO}

2 de abril de 2018

\section{ACEPTADO}

8 de junio de 2018

PUBLICADO

25 de julio de 2018

\section{Formato cita}

Recomendada (APA):

Garay, R.M., Tapia, R., Castillo, M., Fernández, O. y Vergara, J. (2018). Habitabilidad de edificaciones y ranking de discriminación basado en seguridad y sustentabilidad frente a eventuales desastres. Estudio de caso: Viviendas de madera. Revista de Estudios Latinoamericanos sobre Reducción del Riesgo de Desastres REDER, 2(2), pp.28-45

\section{cc) (1)}

Todos los artículos publicados en REDER siguen una política de Acceso Abierto y se respaldan en una Licencia CreativeCommons Atribución-NoComercial 4.0 Internacional.

Revista de Estudios Latinoamericanos sobre Reducción del Riesgo de Desastres (REDER)

Diseño: Lupe Bezzin Tipografía: Hospital 


\section{INTRODUCCIÓN}

En la actualidad, Chile cuenta con un escenario que ofrece oportunidades para la construcción en madera, sin embargo, aún persisten obstáculos por diversos motivos como la alta combustibilidad del material y la fragilidad o precariedad que se asocia a este tipo de viviendas. En el mercado mundial de la madera hay un aumento importante del uso de la misma (Global Wood Industries, 2018; Hildebrandt, 2017; Skullestad, 2016 ) incluyendo su construcción en altura, así como su validación como material sustentable. Tal como analiza Hildebrandt (2017), los productos de madera demuestran su eficiencia como material altamente optimizado y prefabricado, permitiendo proyectos "llave en mano", lo que resulta en tiempos de construcción competitivos en costos. La combinación de estas innovaciones puede abrir un nuevo espacio de oportunidades para la industria de la construcción de la madera en términos de una producción económicamente más viable y energéticamente eficiente (CEPE / FAO, 2013). Los productos, con sus respectivos códigos NACE (estándar de clasificación europeo para actividades económico-productivas) son los productos de madera de ingeniería más relevantes de las industrias de la construcción ecológica: WFIB (C1621), LVL (C1621), Glulam (C1621) y CLT (C1621). Todos estos materiales se producen a escala industrial y su participación en el mercado del sector de la construcción aumenta constantemente. Sin embargo, sus cuotas de mercado siguen estando por debajo del $10 \%$ de las demandas totales del mercado de materiales aislantes y elementos estructurales de construcción. Los materiales de referencia más dominantes se comparan en términos de sus acciones de mercado y emisiones relacionadas con la producción.

Este hecho despierta interés, pero coexiste con la preocupación por incendios (Naciones Unidas, 2010) condición sísmica natural de Chile y la diversidad de climas que caracterizan al país, lo que activa la interrogante de si son suficientes los criterios normativos para asegurar la calidad en las viviendas de madera, considerándose hasta ahora, una respuesta "en construcción”, que está atravesando por modificaciones normativas que se están adoptando (Lignum, 2017). Si bien, existen normativas que cubren los ámbitos de resistencia al fuego, resistencia sísmica, confort térmico, entre otras, es posible notar que la realidad nacional dista bastante de los avances que hay en los países desarrollados con alta cultura de construcción en madera, situación que se contrapone con el potencial que existe en el país por la disponibilidad del recurso y las regiones a las que pertenece.

La normativa vigente aún no es suficiente, y hasta ahora sólo se ha abordado desde la perspectiva de cada criterio técnico analizado en forma aislada: confort térmico, acústico o resistencia sísmica o al fuego. Aunque los arquitectos al diseñar debiesen chequear la compatibilidad de estos criterios técnicos, esto queda sujeto sólo a confiar en su experiencia, pero no a normativas que así lo exijan (Garay, 2016)

Un proyecto de construcción pasa por una secuencia de eventos que parten con el diseño arquitectónico en donde se definen la ubicación y orientación de la(s) vivienda(s), limitación de espacios, planificación, tipo de uso, etc., todo ello, de acuerdo a las exigencias del mandante. El proyecto, posteriormente, avanza al diseño estructural, en donde se especifica con mayor detalle los materiales y dimensiones de los elementos estructurales que le entreguen la resistencia mecánica adecuada; por lo que la construcción, debiera ser un fiel reflejo del diseño. El proyectista realiza esta labor basándose en la normativa legal vigente, tomando en consideración, si así lo estima, recomendaciones del Código de Construcción Sustentable e incluso certificaciones de sustentabilidad y eficiencia internacionales, aunque estas últimas, muy fuera del alcance de proyectos de viviendas sociales.

Lo ideal es que durante todas las etapas de un proyecto, exista una integración y optimización del cumplimiento de los criterios técnicos, por lo que se requiere comunicación y coordinación entre proveedores, mandantes, arquitecto, ingeniero y constructor con respecto a todos los elementos estructurales, no estructurales y materiales que se proyectan para la vivienda, y por cierto, debe conocerse el comportamiento que tendrán estos ante la eventualidad de un incendio. Asumiendo que la obra deberá basarse en dos ejes estructurales ineludibles, la resistencia mecánica y la resistencia al fuego, por lo que los otros criterios deben cumplirse supeditados a los dos primeros. Esto último, por lo general, no es asumido con la relevancia que amerita, pues se diseña y construye sólo bajo las normas existentes. Sin embargo, tras las experiencias, se constata que hay varios aspectos no contemplados, tales como la toxicidad y opacidad de los humos, por ejemplo. En la actualidad, 
las medidas de resguardo que se toman son tan básicas como que el recinto cumpla con los requerimientos mínimos que exige la Ordenanza General de Urbanismo y Construcciones (OGUC), no tomando en consideración que una buena elección de los elementos que compondrán la vivienda, pueden por ejemplo, permitir que el incendio no se propague a otras zonas, o bien, que se apague por el hecho de contar con una buena elección de materiales que garanticen que el fuego no se expanda superficialmente (Hernández, 2008)

La construcción de una vivienda se debe diseñar teniendo en cuenta la relación entre materiales en sus funciones estructurales (Macari, 2015), de protección y preservación de la madera; así como la compatibilidad de los materiales aislantes con la resistencia al fuego, cualidades pirógenas y térmicas de los elementos de construcción, de sus materiales de revestimiento, e incluso, estas cualidades respecto al alhajamiento de las viviendas.

La normativa chilena aborda el comportamiento al fuego de los materiales, elementos y componentes de la construcción de acuerdo a una serie de normas, tales como: normas generales sobre prevención de incendios en edificios, de resistencia al fuego, sobre cargas combustibles en edificios, comportamiento al fuego, señalización en edificios, elementos de protección y combate contra incendios, detectores de humo y rociadores automáticos. Sin embargo, no se cuenta con una norma que clasifique los materiales de revestimientos para que la OGUC pueda hacer alusión a ella, siendo estos los principales causantes de la propagación del fuego dentro del recinto en los primeros segundos, luego de haberse declarado el incendio (Hernández, 2008).

Este trabajo exploratorio, indaga y trae a la discusión normativas extranjeras y la compara con la normativa nacional, que no aborda suficientemente las características pirógenas como temperatura de ignición del material, combustión espontánea, poder calorífico, velocidad de llama, índice de oxígeno, análisis de gases, etc. Y entre las características térmicas, la conductividad térmica y la dilatación térmica sólo se analizan bajo su rol en confort térmico, sin integrarse con su comportamiento frente al fuego. Del análisis del estado actual de la normativa, se plantea la importancia de una reestructuración de la normativa chilena, de manera que se adecúe a las exigencias de los distintos criterios técnicos y que contemple la necesidad de normalizar los tipos de materiales estructurales y de revestimiento que se deben evitar en estructuras destinadas a ciertos usos con el objeto de minimizar el riesgo de incendio, su velocidad de propagación, toxicidad, etc. Todo esto basado en una clasificación de materiales de construcción según su comportamiento al fuego siguiendo el ejemplo de las normativas extranjeras.

Los resultados de la presente investigación, proponen un índice integrado de seguridad y sustentabilidad, una herramienta que pretende abordar una problemática que hasta el día de hoy, no ha sido solucionada, por medio de un análisis Multicriterio, que abarque las temáticas más importantes en la construcción y sea capaz de relacionarlas entre sí. De ese modo, obtener un indicador que señale la seguridad y sustentabilidad de las viviendas, principalmente las de tipo social, con el objetivo de aumentar el conocimiento sobre la construcción en madera, sus reales ventajas y desventajas, además, de contribuir a la mejora de los requisitos ya propuestos en la matriz normativa chilena.

La definición de criterios técnicos no debe entenderse como un mero mejoramiento visual de una vivienda, sino el cumplimiento estricto de un estándar, que se cumple según las disposiciones reglamentarias exigidas por la OGUC, en particular, para las viviendas sociales o económicas, vale decir, se debe demostrar con pruebas y ensayos normalizados el cumplimiento de estos criterios. La validación es clave para transparentar el mercado, de esta forma se estará entregando un producto probado y validado a las personas más vulnerables de la sociedad. Ese es el concepto de estándar que se quiere traspasar a los proveedores y compradores de viviendas y edificaciones en madera, en general.

Se requiere validar los criterios técnicos y poner la información a disposición de quienes la requieran, por ejemplo las autoridades para que se tomen decisiones informadas puesto que existe escasa información que respalde el cumplimiento normativo de las empresas formales e informales de viviendas prefabricadas. Aun, no ha sido posible caracterizar a este sector y describir los sistemas constructivos que ofrecen al mercado, basado en las normativas vigentes. Los datos estadísticos disponibles del sector maderero son de responsabilidad del Instituto Forestal, sin embargo, no incluyen al subsector construcción en madera (INFOR, 2017). 
Ya no es posible que los proveedores se limiten a ofrecer algún producto que presente ciertas mejorías atractivas y que el mercado se conforme con eso. En este ámbito, existe el Registro CDT, que incluye fichas técnicas; referencias técnicas, así como la guía del especificador que ha sido creado y divulgado por la Corporación de Desarrollo Tecnológico (CDT) de la Cámara Chilena de la Construcción (Registro CDT, 2018).

Por ejemplo, cuando se debe cumplir con la normativa de confort térmico en el territorio nacional, significa que se debe probar que esto es efectivamente así, eso va a permitir crear un sistema de características comparables y verificables para el conjunto e interacción de diversos criterios técnicos, no de uno por sobre el otro, tal como la inscripción de soluciones constructivas que existe en la división Técnica del Ministerio de la Vivienda y Urbanismo de Chile (MINVU, 2014).

\section{REFERENCIAS CONCEPTUALES Y NORMATIVAS}

La vivienda, según el enfoque de necesidades y satisfactores de Max Neef, es un satisfactor de necesidades existenciales y axiológicas. (Max Neef et al., 1986). Las cualidades de un satisfactor, incluidas en los bienes económicos, como lo es también la vivienda, conlleva las condiciones de habitabilidad de las mismas. Así entendida la vivienda, sus cualidades de habitabilidad van cambiando a lo largo del tiempo de modo constante, según se mejore su calidad y se invierta o se destine más presupuesto en las políticas públicas de ese sector, entre los principales factores que inciden sobre ella. Aparejado a esos cambios, va ocurriendo lo mismo con sus estándares, los cuales, en cuanto a normas, van definiendo mejores calidades.

En relación a la habitabilidad, su tratamiento adecuado, es parte del bienestar habitacional y ella puede entenderse desde una perspectiva multiescalar. Tal perspectiva parte del considerar que los principales factores que la definen son los de tipo físico-espacial, psico-social, térmico, acústico, lumínico, seguridad y mantención (Jirón et al., 2004).

Por otra parte, la ocurrencia de desastres como consecuencia del comportamiento de la naturaleza, cuando los ecosistemas humanos y naturales no se encuentran en equilibrio, son también oportunidades para poner a prueba y evaluar esas condiciones de habitabilidad, desde el barrio a la vivienda al menos. Sus estándares y resultados finales de su aplicación, en cuanto a colaborar en el mejoramiento de las condiciones de vida de los seres humanos. Los lugares afectados aprenden de cada desastre y los prepara de mejor modo para el próximo desequilibrio (Cutter et al., 2008). Chile está avanzando en estos aspectos y las últimas catástrofes y las respuestas del medio ambiente construido, así lo reafirman (Arteaga \& Tapia, 2014).

El hábitat residencial, en donde predomina la vivienda, no solo incluye aquellas, sino que, aquel puede comprenderse como la articulación de al menos tres dimensiones: la política económica, la socio cultural y la físico-espacial. Cada una de ellas tiene sus propias implicancias internas y externas en un contexto relacional (Campos \& Medic, 2014).

La dimensión físico-espacial comprende la vivienda, el entorno inmediato y un contexto mayor como podría ser un conjunto habitacional, un condominio, un barrio o una comuna. Cada una de estas escalas territoriales o espaciales posee sus particularidades. El presente trabajo, profundiza en la vivienda y sus atributos de habitabilidad, principalmente en su comportamiento de seguridad y mantención.

Es posible que un factor deficientemente tratado en la seguridad y mantención de la vivienda sea el definido como constructividad y que alude al grado en que un diseño permite una mayor adecuación, facilidad y eficiencia de construcción entre aquel y los requerimientos del diseño y del mandante (Loyola \& Goldsak, 2010). Aquel factor requeriría un análisis en profundidad, tomando en cuenta que de acuerdo al modelo de provisión habitacional chileno, en el diseño y construcción de las viviendas, interviene mayormente el sector privado y la cualidad de aquel, pasa a segundo plano. Las exigencias relevantes por las cuales se rigen los proyectistas son las que se derivan de los cuerpos normativos y a estos, los crean determinados observadores para disminuir riesgos según sus particulares intereses (Lhumann, 1998).

En la definición de calidad habitacional, confluyen factores objetivos y subjetivos (Toro et al., 2003). Entre los primeros, como ya se indicó, están aquellos alusivos a la seguridad y mantención, dentro de los cuales se ubica la calidad de una edificación, para el caso, aquella con fines habitacionales. La presente investigación enfatiza las cualidades constructivas en relación al 
comportamiento al fuego de edificaciones con destino habitacional.

Resistencia al Fuego. Es la cualidad de un elemento de construcción de soportar las condiciones de un incendio sin menoscabo de su función estructural y evitando que el incendio se transmita hacia el recinto contiguo al que el elemento separa. Esta cualidad se mide por el tiempo durante el cual el elemento conserva la estabilidad mecánica, la estanquidad a las llamas, el aislamiento térmico y la no emisión de gases inflamables.

Existen dos variables que influyen en la rapidez con que se producen las etapas de un incendio:

1. La Carga de combustible contenida al interior de la vivienda (Velásquez, 2010).

2. El Sistema constructivo utilizado, este puede oponerse en mayor o menor medida al avance de las llamas, dependiendo de los revestimientos de protección y barreras físicas utilizadas (Velásquez, 2010)

Primera etapa/Inicio. En esta etapa ocurre el desarrollo inicial, existe oxígeno adecuado y la combustión es relativamente completa, debido a esto, el incendio es más rápido, las llamas más vigorosas y la emisión de humo y calor son mínimos. Las temperaturas que se alcanzan van desde los 35 a $400{ }^{\circ} \mathrm{C}$ (Velásquez, 2010).

Segunda etapa/ Crecimiento. Dentro de esta etapa el incendio es muy difícil de controlar y la combustión de los elementos inflamables dentro de la vivienda es muy rápida. Además, la capacidad de resistencia de la estructura se ve afectada negativamente a medida que continúa el incendio. Pronto se consume el oxígeno y desciende su cantidad hacia el lugar del fuego. En ella aumentan las llamas y la temperatura sube de 400 a $550^{\circ} \mathrm{C}$ (CORMA, 2007).

Tercera etapa/ Declinación Por ser una etapa de decline, el contenido de oxígeno ya no es suficiente para continuar con la combustión, por lo que el fuego retrocede hasta su punto de origen y posteriormente se mantiene en forma de brasas. La emisión de calor es muy elevada, con temperaturas de 550 hasta $1100{ }^{\circ} \mathrm{C}$ (CORMA, 2007).

Esta etapa es la parte más peligrosa, puesto que la combustión incompleta emite un humo denso, el cual se queda atrapado en el interior del edificio, en conjunto con los gases combustibles sobrecalentados, los cuales no a llegan inflamarse por la falta de oxígeno. En el momento de que ingrese aire al lugar antes de evacuar los gases, se puede provocar una explosión súbita llamada back-draft (explosión de humo), la cual genera bastante daño a las estructuras y a las personas presentes (Velásquez, 2010).

La estructura de la vivienda colapsa y las llamas declinan, puesto que el material combustible ya ha sido consumido casi en su totalidad (Velásquez, 2010). En ocasiones, la falta de conocimientos presente en las personas les permite subestimar la peligrosidad de los humos, temperaturas y avance del incendio, por lo que, muchas veces la muerte de personas se debe a que estas vuelven a entrar en la vivienda incendiada, con el objetivo de salvar bienes materiales e incluso a seres queridos (Velásquez, 2010).

1. Carga combustible: Prevención de incendio en edificios. Clasificación de los edificios según su densidad de carga combustible (NCh 1993 Of. 87).

La posibilidad que un fuego inicial producido en un edificio se convierta en un incendio desastroso depende, entre otros factores, de la densidad de carga combustible que tenga y de su distribución. En consecuencia, es de utilidad clasificar los edificios según su densidad de carga combustible y su densidad de carga combustible puntual, la que variará según los materiales empleados en la construcción, en el alhajamiento y en el uso a que se destine el edificio.

En Chile, se establecen seis categorías para clasificar los edificios o sectores de ellos según su densidad de carga combustible y su densidad de carga combustible puntual máxima. Dicha clasificación se encuentra en la Tabla 1. La determinación de la carga de combustible nace de la necesidad de estimar el riesgo de que un eventual fuego se convierta en incendio (NCh 1916 Of. 1999), ésta carga depende de la cuantía y calidad pirógena de los materiales utilizados para la construcción de un edificio (NCh 1916 Of. 1999). 


\begin{tabular}{|c|c|c|}
\hline Clasificación & $\begin{array}{l}\text { Densidad de Carga Combustible } \\
\mathrm{MJ} / \mathrm{m}^{2}\end{array}$ & $\begin{array}{l}\text { Densidad de Carga Combustible } \\
\text { Puntual Máxima } \mathrm{MJ} / \mathrm{m}^{2}\end{array}$ \\
\hline Dc 1 (baja) & Hasta 500 & Hasta 750 \\
\hline Dc 2 (media baja) & Más de 500 hasta 1000 & Más de 750 hasta 1500 \\
\hline Dc 3 (media) & Más de 1000 hasta 2000 & Más de 1500 hasta 3000 \\
\hline Dc 4 (media alta) & Más de 2000 hasta 4000 & Más de 3000 hasta 6000 \\
\hline Dc 5 (alta) & Más de 4000 hasta 8000 & Más de 6000 hasta 12000 \\
\hline DC 6 (especial) & Más de 8000 & Más de 12000 \\
\hline
\end{tabular}

La norma chilena NCh 1914 Of. 84 de Prevención de incendio en edificios Ensayo de reacción al fuego. Parte 1: Determinación de la no combustibilidad de materiales de construcción, establece un método de ensayo relativo a uno de los aspectos de la reacción al fuego de un material. Este método permite valorar la característica de dicho material a emitir, en las condiciones del ensayo, un calor superior a un nivel dado o a emitir, en las condiciones del ensayo, un calor superior a un nivel dado o a emitir llamas. Se aplica a los materiales o productos de construcción y/o edificación, que hayan recibido o no una capa de acabado; no es aplicable a la materia empleada en el acabado.

Actualmente existen estudios de carga combustible obligatorios para recintos industriales ya que la Ordenanza General de Urbanismo y Construcción (OGUC) lo establece así, sin embargo, este tipo de estudios aún no son de carácter obligatorio para viviendas, por lo cual se propone avanzar en la regulación de este ámbito.

Matriz multicriterio. La evaluación multicriterio es un conjunto de técnicas que ayudan a la toma de decisiones (Voogd, 1983, p. 21) que permiten jerarquizar los distintos problemas y las opciones de acuerdo a su grado de atracción (Janssen \& Rietveld, 1990, p. 129).

Los análisis multicriterio y los modelos de decisión multiobjetivo entregan un análisis equilibrado de todas las facetas de los problemas de planificación (Nijkamp \& Van Delft, 1977) lo que en la planificación territorial, abarcaría cada una de las partes del territorio susceptibles de ser evaluadas (Gómez \& Barredo, 2005, p. 48).

Existen dos tipos de criterios utilizados para la asignación de valores dentro de la matriz: Los factores y los limitantes; un factor corresponde a un criterio que aprueba o desaprueba la capacidad de asentamiento de una alternativa específica para la actividad en consideración (Eastman et al., 1993, p. 2) mientras que el limitante restringe la disponibilidad de las opciones en función de la actividad analizada, este criterio genera una capa binaria donde un código muestra la disponibilidad de las alternativas susceptibles a utilizar y otro muestra la no disponibilidad.

\section{Normativa vigente respecto a la regulación del fuego en edificios}

En la tabla 2, se resume la normativa oficial de prevención de incendios en edificios y en la Tabla 3, la clasificación de elementos constructivos según su resistencia al fuego.

\begin{tabular}{l} 
Acrónimo de la norma y número y/o año - temática \\
\hline NCh 382 Of. 98 - "Sustancias peligrosas - Terminología y clasificación general" \\
\hline NCh 1411 Of. 78 - "Identificación de riesgos de materiales" \\
\hline NCh 2120 /1 al 9/ Of. 89 - "Sustancias peligrosas - Parte 1 al 9: Clases 1 al 9" \\
\hline NCH 2137 Of. 92 - "Sustancias peligrosas - Embalajes/envases - Terminología, clasificación y designación” \\
\hline NCh 933 - Terminología \\
\hline NCh 934 - Clasificación de fuegos \\
\hline NCh $935 / 1$ - Ensaye de resistencia al fuego - Parte 1: "Elementos de construcción general” \\
\hline NCh $935 / 2$ - Ensaye de resistencia al fuego - Parte 2i: "Puertas y otros elementos de cierre" \\
\hline NCh 2209 - "Ensaye del comportamiento al fuego de elementos de construcción vidriados" \\
(Continúa en la siguiente página)
\end{tabular}


(Continuación)

NCh 1914/1 - Ensaye de reacción al fuego Parte 1: Determinación de la no combustibilidad de materiales de construcción"

NCh 1993 - "Clasificación de los edificios según su carga combustible"

NCh 1974 - "Pinturas - Determinación del retardo al fuego"

NCh 1977 - "Determinación del comportamiento de revestimientos textiles a la acción de una llama"

NCh 1979 - Determinación del comportamiento de telas a la acción de una llama

NCh 2189 - "Seguridad - Señalización de edificios - Condiciones básicas"

Tabla 2. Normas chilenas de seguridad y control de incendio Fuente: Autores, 2018, basado en DS.594/99 MINSAL CHILE

\begin{tabular}{lll} 
Clase & \multicolumn{2}{l}{ Duración (minutos) } \\
\hline$F 0$ & $\geq 0$ & $<15$ \\
\hline$F 15$ & $\geq 15$ & $<30$ \\
\hline$F 30$ & $\geq 30$ & $<60$ \\
\hline$F 60$ & $\geq 60$ & $<90$ \\
\hline$F 90$ & $\geq 90$ & $<120$ \\
\hline$F 120$ & $\geq 120$ & $<150$ \\
\hline$F 150$ & $\geq 150$ & $<180$ \\
\hline$F 180$ & $\geq 180$ & $<240$ \\
\hline$F 240$ & $\geq 240$ & \\
\hline
\end{tabular}

Tabla 3. Clasificación de elementos constructivos según su resistencia al fuego Fuente: NCh 1914 Of84

El cuestionamiento suele provenir de viviendas de madera mal diseñadas, que han mostrado llamas que se pueden propagar tan rápidamente que, en 2 minutos, puede extenderse por toda la habitación donde empezó el fuego. En 3 minutos, todo lo que hay en una habitación puede calentarse lo suficiente como para estallar en llamas. En 5 minutos, dicha vivienda puede estar completamente en llamas (Velásquez, 2010).

Este análisis enmarca la importancia del diseño de las viviendas en cuanto a la disposición de los elementos y materiales. Tomando en cuenta los tiempos de resistencia que pueden soportar los elementos constructivos de una vivienda, incluyendo las condiciones exteriores e interiores de la misma, generando un índice integral que permita prevenir el riesgo, lo que ayudaría a generar construcciones mucho más sustentables en el tiempo y bastante más seguras para la población.

La investigación desde la cual se desprende el presente trabajo, tiene como objetivo general el diseñar un índice integral de seguridad y sustentabilidad (IISS) para la construcción en madera para las zonas de interfaz urbano rural en la comuna de San José de Maipo en Santiago de Chile, en donde sea posible incluir los criterios evaluativos de la Ordenanza General de Urbanismo y Construcción (OGUC), y el código de construcción sustentable (CCS) por medio de una matriz Multicriterio. Para ello, se revisan e integran las normas técnicas vigentes para viviendas (OGUC, CCS) y se compararán con las normas de protección contra el fuego para proponer modificaciones.

\section{MATERIAL}

Se utilizó, de modo experimental, un prototipo de vivienda modular fabricada en Paneles "SIP", instalada en la comuna de La Pintana, Región Metropolitana, Santiago, CHILE.

El mencionado prototipo, se diseñó, fabricó e instaló, de modo tal que cumpliese con criterios técnicos mínimos de habitabilidad, que garantizaran protección a las personas en distintos ámbitos de seguridad y confort, por lo que se adoptó como materialidad principal para su fabricación, los paneles SIP que son descritos a continuación.

Los paneles SIP son paneles estructurales aislantes; conformados por un núcleo sin uniones, de material aislante térmico rígido y dos placas de comportamiento mecánico homogéneo; material que va unido con un adhesivo permanente de uso estructural, logrando un elemento solidario 
con capacidad para absorber solicitaciones estructurales. (INN, 2016). Las dimensiones en este estudio son 1,22 × 2,44 m, con un espesor total de $64 \mathrm{~mm}$ (en adelante SIP64), y su estructura básica está compuesta por:

- $\quad$ Alma: Poliestireno expandido de alta densidad (INN 1983; INN 1984) 15 kg/m³ y 45 mm de espesor.

- $\quad$ Caras: Tableros estructurales de madera tipo OSB Standard, 1,22 × 2,44 m y 9,5 mm.

- Adhesivo: En base a poliuretano mono o bi componente fragüe bajo presión y a alta temperatura.

Los detalles de los paneles se muestran en la Figura 1.

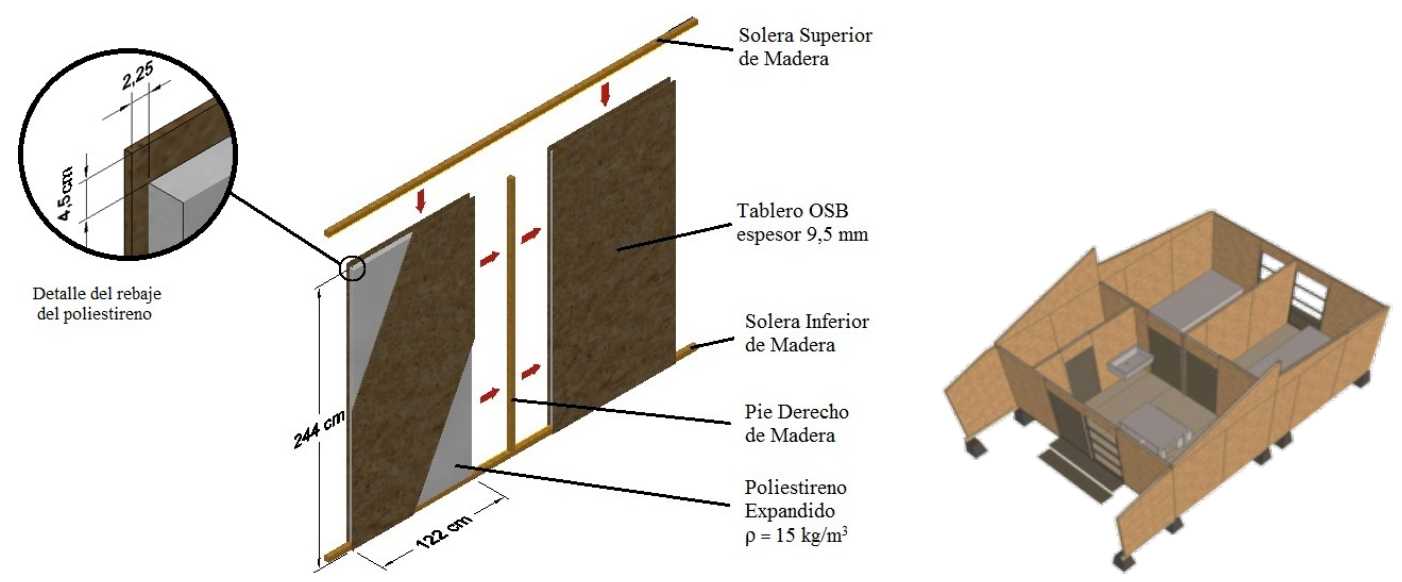

Figura 1. Sistema constructivo de muros y vista en 3D Fuente: Autores, 2018

Los prototipos se construyeron con paneles SIP $64 \mathrm{~mm}$ en el espesor de aislación, incorporando una unión de pie derecho de $45 \times 45 \mathrm{~mm}$ (Figura 1), consecuentemente la resistencia mecánica de esta estructura es superior al sistema de unión patentado en $75 \mathrm{~mm}$. Se sabe que los puentes térmicos se deben más a filtraciones de aire que al espesor del aislante, fallas de aislación, rendijas, ventanas y puertas, entre otras causas similares, entonces se privilegió evitar tales puentes y se fijó el espesor en $64 \mathrm{~mm}$, manteniendo el espesor de los tableros OSB en 9,5 mm y el aislante en muros a $45 \mathrm{~mm}$, al igual que los pies derecho y soleras superior e inferior. Esta estructura es liviana y fácil de montar (peso aproximado $32 \mathrm{Kg} /$ panel).

Además, estas estructuras fueron diseñadas para que puedan ser fabricadas (Figura 2) en un taller con baja, mediana o alta implementación técnica, pues se estableció como propósito, transferir la tecnología industrializada de fabricación de los paneles SIP a cualquier nivel de ejecución técnica. Particularmente se usó adhesivo de fraguado en frío mono componente aplicable con llana y presión ejercida por carga estática repartida transversalmente, así como prensas automatizadas de uso habitual en esta tecnología.

Los espesores de aislación en muros $(45 \mathrm{~mm})$ se mantuvieron constantes para todos los prototipos, independiente de la zona climática para evitar diferenciar más componentes, los que sí deben ser diferenciados son pisos y techumbres, como se explica más adelante.

Aunque el mapa climático de Chile describe zonas climáticas extremas en distintas partes del territorio, es un hecho que en cada región, así como hacia la cordillera, tales zonas se vuelven más extremas. En un análisis global, se puede analizar el país en tres grandes zonas, así las viviendas en la zona norte, son preferentemente zonas climáticas 1 y 2, requieren ventilación, la protección exterior debe ser fundamentalmente frente a la irradiación solar, más que a efectos de lluvia, el confort térmico debe apuntar a proveer enfriamiento de día y mantención del calor en la noche. Otro aspecto relevante a contemplar es la ubicación en áreas de riesgo, peligros como excesiva carga combustible por zonas de interfaz urbano forestal o su cercanía a zonas de deslizamiento o inundaciones deben ser estudiadas en profundidad. 
Por su parte en la zona central, mayoritariamente condiciones climáticas zona 3, 4 y 5, las condiciones de protección no son extremas, como fríos muy intensos o temperaturas muy altas, pero existen ambas condiciones además de lluvia que puede ser abundante. Por lo que la habitabilidad de estas viviendas debe procurar protección frente a diversos efectos climáticos. En concreto, la protección exterior debe ser resistente a lluvia y temperaturas altas y bajas, irradiación solar intermedia, los cambios climáticos entre invierno y verano son más marcados, por lo que debe procurarse un buen sellado y una buena condición de ventilación para cubrir ambas necesidades cuando el criterio a resolver es el confort térmico.

En el extremo sur, preferentemente zonas climáticas 6 y 7, las condiciones son más lluviosas, menores cambios de temperatura entre el día y la noche. Sin embargo, debido al cambio climático se observa temperaturas inusualmente altas si se analizan estadísticas históricas, por lo que la ventilación en verano es un tema de preocupación, pero es más gravitante la protección al frío en estas zonas, por lo que se considera más relevante la estanquidad al agua y sellado como criterios para estas condiciones. Estos criterios, se muestran en las Figura 2 con las diferencias que tendrán las viviendas según la condición climática.
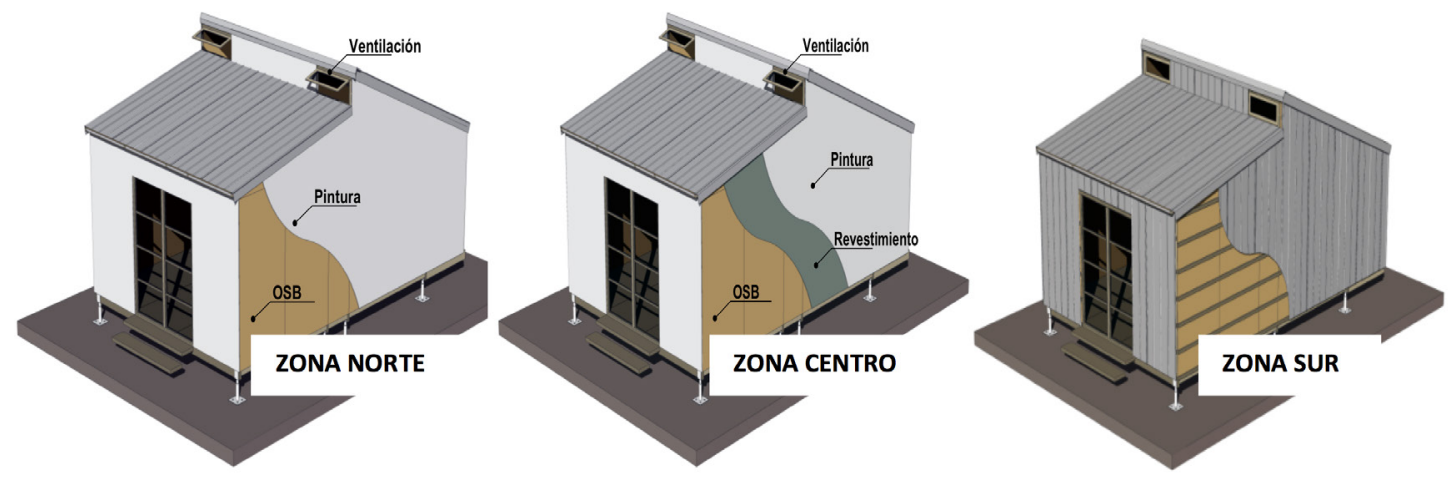

Figura 2. Detalles terminaciones exteriores Zona Norte, Centro y Sur Fuente: Autores, 2018

En la Figura 3 se presenta los planos de arquitectura y una fotografía de las viviendas fabricadas.
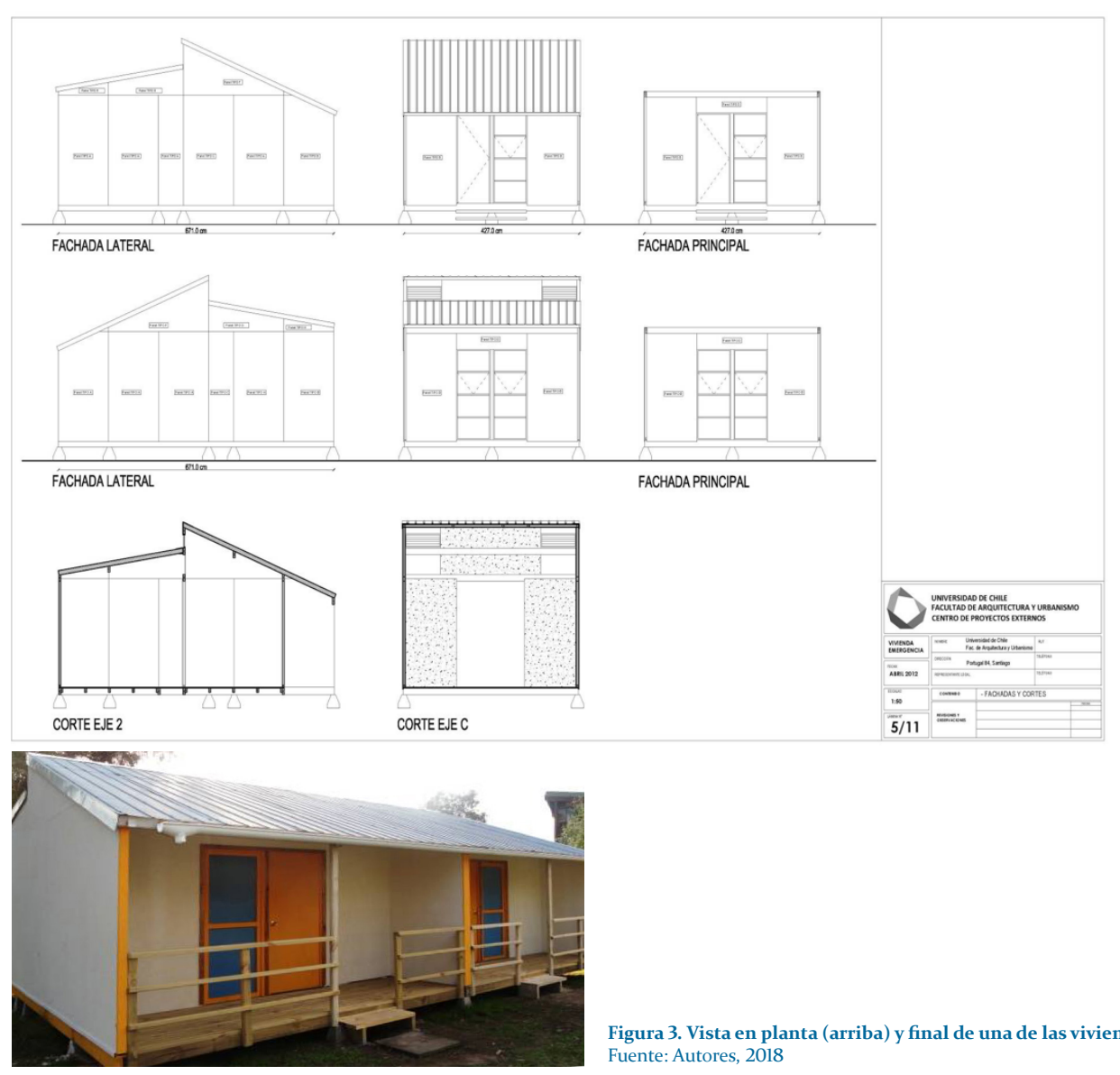

Figura 3. Vista en planta (arriba) y final de una de las viviendas pareadas (abajo) Fuente: Autores, 2018 
Para las terminaciones exteriores de protección superficial se protegió los muros y la madera con esmalte al agua a dos manos, más aplicación de estuco elastómero. En cambio en la zona sur, se revistió los muros con zinc $5 \mathrm{~V}$ y luego se terminó con pintura del tipo acrílica especialmente formulada para las planchas de cubierta, tipo "zincalum" aplicada a dos manos, tanto en techumbre como en muros.

Pequeñas modificaciones fueron introducidas a los diseños, la conformación de los pisos cambia según los requerimientos de cada zona, las ventanillas superiores de ventilación (Figura 2), son más altas y se pueden abrir en la zona norte y central, en el sur son más bajas y permanecen cerradas, permitiendo el paso de luz. Asimismo, en el norte las puertas de acceso traseras de la vivienda son hasta el piso, permitiendo mejorar la ventilación y en el sur sólo son hasta la mitad del muro. Así mismo la terraza frontal ha sido protegida de la lluvia directa en el extremo sur, en cambio en el norte permanece completamente abierta.

La OGUC establece para las viviendas sociales en Chile la obligatoriedad de uso de madera tratada para todos los componentes estructurales, en piso, muros y techo, esta condición no siempre se cumple para todo tipo de viviendas, está más arraigado el cumplimiento para la fabricación de vigas impregnadas para pisos, cerchas y menos arraigado en tabiquería de muros. Para esta investigación, en donde es importante equilibrar los costos y los beneficios, se optó por dar cumplimiento a la normativa en pisos, incorporando vigas impregnadas de $2 \times 6$ " y el resto de la madera utilizada correspondió a madera seca dimensionada sin impregnar ya que la madera siempre queda protegida de exposición directa a la intemperie.

\section{MÉTODO}

Para generar el índice integrado es necesario comprender que se requiere trabajar definiendo prioridades de protección, aunque se intente una protección multipropósito, el aseguramiento queda definido por los eventos que pudieran ocasionar daño. En este sentido, para el caso de incendios forestales de interfaz, tal como se define en el estándar Community Wildfire Safety Through Regulation de National Fire Protection Association (NFPA, 2011), las acciones de protección se ubican a distintos niveles, Las cuatro escalas reglamentarias abordadas en la mencionada guía son:

1. Escala de la comunidad;

2. Escala de vecindad/subdivisión;

3. Individuo escala de propiedad

4. Escala de estructura.

Para responder a la pregunta, de cómo adoptar regulaciones frente a incendios forestales, los distintos países optan por medidas de mitigación para abordar el riesgo que pueden generar fuertes discusiones y a menudo opiniones conflictivas dentro de una comunidad. Un acercamiento exitoso a las regulaciones IFII deben anticipar y abordar los desafíos siguiendo la secuencia metodológica que se exponen a continuación (Figura 4) como pasos a seguir antes de la adopción de medidas de mitigación.

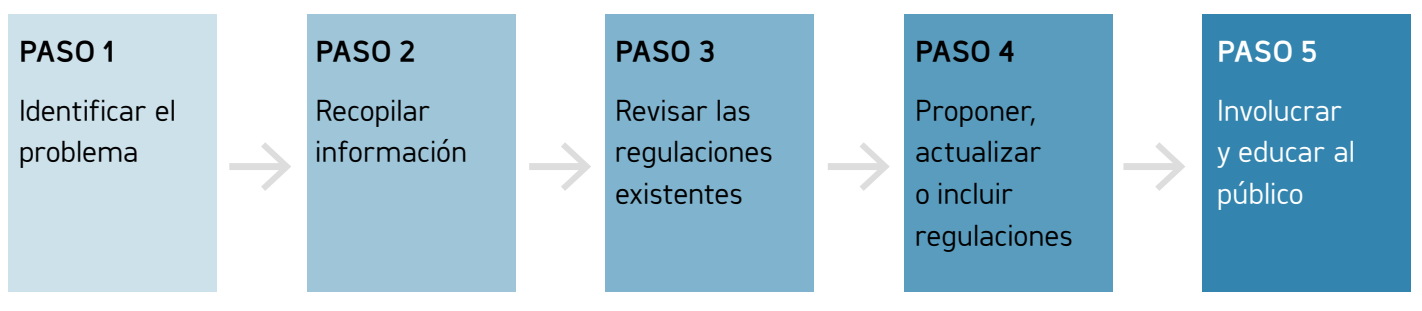

Figura 4. Sequencia para la adopción de medidas de mitigación Fuente: Autores, 2018

Un tema relevante, pero no abordado en términos normativos se refiere a que las comunidades necesitan decidir a qué escala(s) están dispuestos y son capaces de regular. Por lo que esta metodología, intenta abordar dos niveles de la escala que pueden ser más cercanos a las personas, pues les permite comprender en primer lugar, la importancia de la seguridad de su vivienda, es decir lo que corresponde a la edificación unitaria y a las estructuras de los elementos. Se esboza, 
hacia el final de los resultados cómo se construye en análisis de la situación más compleja, de manera de ir sumando niveles a través de los análisis multicriterio que se exponen a continuación.

\section{Matriz Multicriterio}

El desarrollo de la matriz implica ingresar los criterios (Tabla 4) que deben estar presentes en la evaluación y que permiten generar un rating de preferencias (Tabla 5) utilizando los índices aleatorios de Satty (Tabla 6).

\begin{tabular}{ll} 
Criterios OGUC & Criterios CCS \\
\hline 1. Resistencia sísmica & 6. Entorno inmediato \\
\hline 2. Resistencia al Fuego & 7. Impacto ambiental \\
\hline 3. Confort térmico & 8. Residuos \\
\hline 4. Hermeticidad agua/aire & 9. Materiales \\
\hline 5. lluminación y Ventilación & 10. Energía \\
\hline
\end{tabular}

Tabla 4. Criterios técnicos obligatorios y Voluntarios Fuente: Elaboración en base a OGUC y Códigos de Construcción Sustentable. MINVU. 2016

\begin{tabular}{cl} 
Rating & Comparación \\
\hline 1 & igualmente preferida \\
\hline 3 & moderadamente preferida \\
\hline 5 & fuertemente preferida \\
\hline 7 & muy fuertemente preferida \\
\hline 9 & extremadamente preferida \\
\hline 2, 4, 6, 8 & rating recíproco \\
\hline Tabla 5. Rating de Comparación \\
Fuente: Saaty, 1980
\end{tabular}

\begin{tabular}{cc} 
Total de alternativas & índice aleatorio (RI) \\
\hline 3 & 0,58 \\
\hline 4 & 0,9 \\
\hline 5 & 1,12 \\
\hline 6 & 1,24 \\
\hline 7 & 1,32 \\
\hline 8 & 1,41 \\
\hline
\end{tabular}

Tabla 6. Índice aleatorio de Satty Fuente: Saaty, 1980

Luego de definir los criterios se procede al modelamiento del índice, para ello se utiliza el modelo de proceso analítico jerárquico de Thomas Saaty, que se divide en 8 etapas.

- Descomponer el problema de decisión en una jerarquía de elementos interrelacionados: Se deben identificar a) meta general, b) los criterios ( $(=1,2,3 \mathrm{~m}$ ) c) las alternativas $(j=1,2,3 n)$. Para cada uno de los " $m$ " criterios se deben repetir las etapas (2) a (5).

- Desarrollar la matriz de comparación por pares (MCP) en este paso se obtienen los ratings de importancia relativa entre las alternativas consideradas para cada uno de los criterios. Cuando se realiza la comparación de una alternativa con si misma se le asigna el valor 1 .

Para ello se debe utilizar una escala que se señala a continuación:

- Desarrollar la matriz normalizada (MCN) dividiendo cada número de una columna de la MCP, por la suma total de la columna.

- Generar el vector de prioridad para el criterio calculando el promedio de cada fila de la MCN. Este promedio por fila representa el vector de prioridad de la alternativa con respecto al criterio considerado.

- La consistencia de las opiniones utilizadas en la MCP puede ser determinada a través del cociente de consistencia (RC). Un CR inferior a 0,10 es considerado aceptable. Para aquellos los casos en que CR sea mayor a 0,10, se deberá considerar nuevamente las ponderaciones. *El Cálculo del Cociente de consistencia se detalla más abajo.

- Luego de que la secuencia (2) - (3) - (4) - (5) ha sido ejecutada para todos los criterios, los resultados obtenidos en (4) son resumidos en una matriz de prioridad (MP), listando las alternativas por fila y los criterios por columna.

- Desarrollar una matriz de comparación de criterios por pares de manera similar a lo que se hizo para las alternativas en (2)- (3)- (4).

- Desarrollar un vector de prioridad global multiplicando el vector de prioridad de los criterios (7) por la matriz de prioridad de las alternativas (6).

La determinación del cociente de consistencia, se realiza por medio de 6 etapas:

- Para cada línea de la matriz de comparación por pares, determinar una suma ponderada en base a la suma del producto de cada celda por la prioridad de cada alternativa correspondiente.

- Para cada línea, dividir su suma ponderada por la prioridad de su alternativa correspondiente. 
- $\quad$ Determinar la media $\lambda$ máx del resultado de la etapa (2)

- Calcular el índice de consistencia para cada alternativa $C I=\frac{(\lambda m a ́ x-n)}{(n-1)}$

- $\quad$ Determinar el índice RI de la tabla 5.

- Determinar el cociente consistencia (CR): $\mathrm{CR}=\mathrm{Cl} / \mathrm{RI}$

En el caso de Incendios, es común que la normativa incluya un análisis de este criterio en aquellas edificaciones, que por su destino, requieran de un informe de carga combustible, dada la magnitud el impacto que pudiese tener un eventual incendio, como es el caso de dependencias que usen grandes volúmenes de solventes volátiles, combustibles, como una fábrica de pinturas, de plásticos o similares. Sin embargo, esta normativa sirve para comprender la magnitud del combustible presente en un incendio forestal de interfaz, que potencialmente puede afectar edificaciones y entornos que aporten gran cantidad de biomasa, madera e incluso compuestos tóxicos almacenados sin ninguna regulación especial. Por esta razón, el método plantea su inclusión como un factor a tener en cuenta en la evaluación y su posible inclusión en regulaciones distintas a las en que actualmente se emplea.

\section{Carga de combustible}

Para hacer el cálculo de la carga de combustible es necesario realizar con antelación un inventario del lugar, esto implica realizar un dimensionamiento de la superficie del recinto o de las superficies, comenzando por la medición de altura de las habitaciones, a esto se le debe incluir las características de los materiales de cierre, separaciones y tabiquería (NCh 1916 Of. 99). Por último, se debe especificar los elementos almacenados en el interior de cada compartimiento, diferenciando por tipo de objeto y material de composición (NCh 1916 Of. 99)

Una vez reconocido los materiales de composición, se les asigna un valor predeterminado de calor de combustión, el cual está designado según la Norma Oficial Chilena NCh 1916 Of. 99 "Prevención de incendios en edificios - Determinación de cargas combustibles".

La carga de combustible se calcula por medio de la siguiente fórmula:

$$
C=C c \times M_{1}+C c_{2} \times M_{2}+\ldots C c_{n} \times M_{n}
$$

En donde $C$ es la carga de combustible expresada en $\mathrm{MJ}$ o Mcal, $C c$ corresponde al calor de combustión de los materiales combustibles integrantes, expresados en $\mathrm{MJ} / \mathrm{kg}$ o Mcal $/ \mathrm{kg}$., y $M$ corresponde a la masa de los materiales combustibles integrantes, de calores de combustión $C c$, expresadas en $\mathrm{kg}$

Para su utilización se debe conocer previamente la cantidad de los materiales involucrados, además de la composición de los objetos. De esta forma, se obtiene un cálculo estimado de la carga de combustible para un lugar determinado. Para finalizar se divide el total de la carga combustible por el área del lugar y así se obtiene la densidad media de carga de combustible.

Para el cálculo de la densidad de carga de combustible puntual máxima se utiliza la norma NCh 1993 Of. 98, que establece un método para corregir eventuales distorsiones debido a almacenamientos puntuales. Para ello, se considera un área de $2 \times 2 \mathrm{~m}\left(4 \mathrm{~m}^{2}\right)$ donde exista la mayor densidad de carga combustible.

\section{RESULTADOS Y DISCUSIÓN}

Se diseñó, fabricó y evaluó viviendas modulares fabricadas en paneles SIP. Basado en Especificaciones técnicas que se generaron, se sistematizó la información según el índice que se muestra en la Tabla 7. 


\begin{tabular}{ll} 
Índice & \\
\hline 1.1 Introducción & 3.4. Revestimientos Exteriores \\
\hline 1.2 Gastos adicionales y obras preliminares & 3.5 Tratamiento de Fachadas \\
\hline 2 Obra gruesa & 3.6. Revestimientos Interiores \\
\hline 2.1. Excavaciones y movimientos de tierra & 3.7 Cielos \\
\hline 2.2 Estabilización del terreno & 3.8 Pavimentos \\
\hline 2.3 Fundaciones y Cimientos & 3.9 Puertas \\
\hline 2.4 Sobrecimientos & 3.10 Ventanas \\
\hline 2.5 Bases de Pavimentos & 3.15 Pinturas y Barnices \\
\hline 2.6 Estructura Resistente & 4 Instalaciones \\
\hline 2.7 Elementos verticales no soportantes & 4.1. Agua Potable \\
\hline 2.10 Estructura de Techumbre & 4.2. Instalación Alcantarillado \\
\hline 2.11 Cubiertas & 4.3. Artefactos Sanitarios \\
\hline 3 Terminaciones & 4.4. Evacuación de Aguas lluvias \\
\hline 3.1. Comportamiento al Fuego & 4.6. Instalaciones Eléctricas \\
\hline 3.2. Aislación Térmica & 4.9.Instalaciones domiciliarias de combustible \\
\hline 3.3. Aislación Acústica & 5 Planimetría \\
\hline
\end{tabular}

Tabla 7. Índice de Especificaciones Técnicas consideradas en las viviendas Fuente: Autores, 2018

Tanto las Edificaciones como los Elementos Constructivos Prefabricados que se integren al proyecto deben cumplir con los criterios técnicos que se especifican en la Tabla 8.

\begin{tabular}{|c|c|c|c|c|}
\hline Criterio Técnico & Escala Edificación & Escala Elemento & Nivel* $^{*}$ & Ponderación IISS \\
\hline 1 & $\begin{array}{l}\text { Resistencia Mecánica, de la } \\
\text { Edificación Exigible sólo a grandes } \\
\text { obras de Ingeniería }\end{array}$ & $\begin{array}{l}\text { Ensayos de Resistencia } \\
\text { Mecánica, del elemento cons- } \\
\text { tructivo elegido. Panel SIP } 64\end{array}$ & $\mathrm{~B}$ & 0,3 \\
\hline 2 & $\begin{array}{l}\text { Elementos y Normativas de } \\
\text { Resistencia al Fuego Exigibles sólo a } \\
\text { edificios en Altura y Grandes Obras }\end{array}$ & $\begin{array}{l}\text { Resistencia al Fuego, del } \\
\text { elemento constructivo elegido } \\
\text { Panel SIP } 64\end{array}$ & $\mathrm{~B}$ & 0,3 \\
\hline 3 & $\begin{array}{l}\text { Estudio del Comportamiento } \\
\text { Térmico. Exigibles a Todas las } \\
\text { Viviendas sociales }\end{array}$ & $\begin{array}{l}\text { Comportamiento Térmico del } \\
\text { elemento constructivo elegido. } \\
\text { Panel SIP } 64\end{array}$ & $\mathrm{~B}$ & 0,3 \\
\hline 4 & $\begin{array}{l}\text { Verificación estructural Exigible sólo } \\
\text { a estructuras de mayor envergadura }\end{array}$ & $\begin{array}{l}\text { Verificación estructural del } \\
\text { elemento constructivo elegido. } \\
\text { Panel SIP } 64\end{array}$ & $M$ & 0,6 \\
\hline 5 & $\begin{array}{l}\text { Comportamiento acústico, según } \\
\text { condición de uso: Hospitales, discote- } \\
\text { ques, viviendas }\end{array}$ & $\begin{array}{l}\text { Comportamiento acústico del } \\
\text { elemento constructivo elegido. } \\
\text { Panel SIP } 64\end{array}$ & $M$ & 0,3 \\
\hline
\end{tabular}

Tabla 8. Ponderaciones para Índice de Seguridad y Sustentabilidad (IISS)

Fuente: Autores, 2018

* $\mathrm{B}=$ Básico; $\mathrm{M}=$ Medio; $\mathrm{A}=$ Avanzado

\section{Evaluaciones Técnicas}

1.- Verificación Mecánica. La Figura 5 enseña muestras de los resultados de las evaluaciones y estandarización mecánica de los elementos estructurales de la Vivienda, para este ejemplo Paneles SIP.

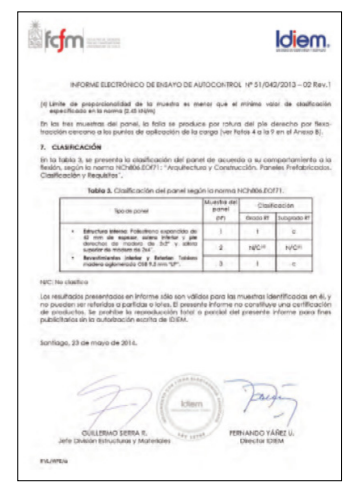

(Continúa en la siguiente página)
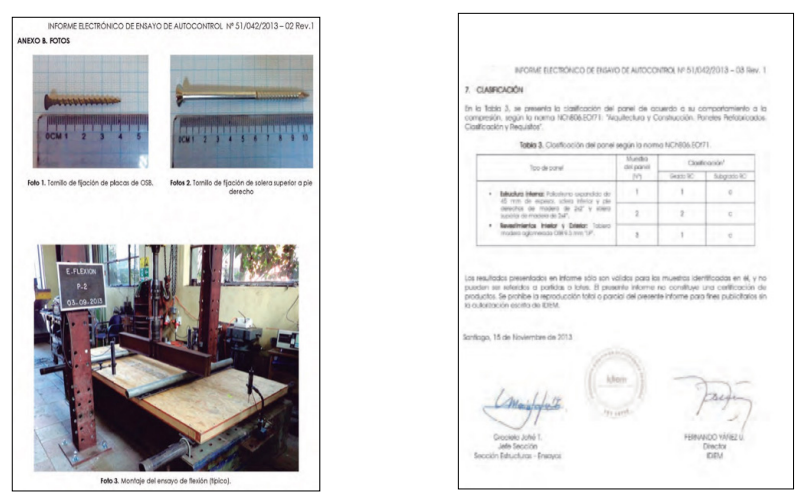

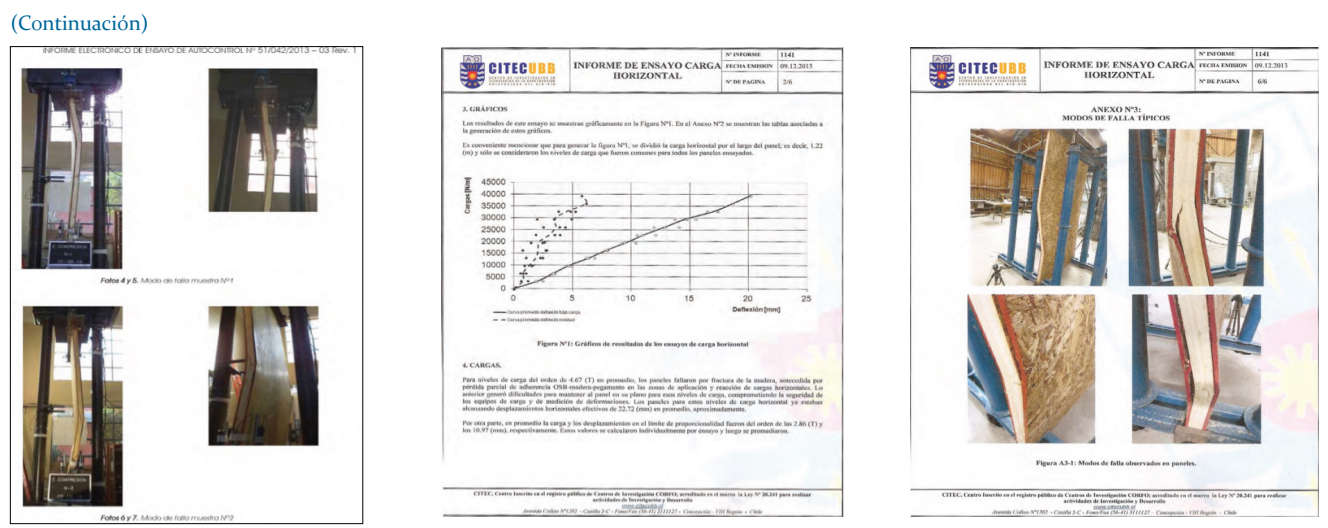

Figura 5. Muestras de los resultados de las evaluaciones mecánicas Fuente: Autores, 2018

2. Verificación Resistencia al Fuego. La Figura 6 enseña muestras de los resultados de las evaluaciones de resistencia al fuego de los elementos estructurales de la Vivienda, para este ejemplo Paneles SIP.
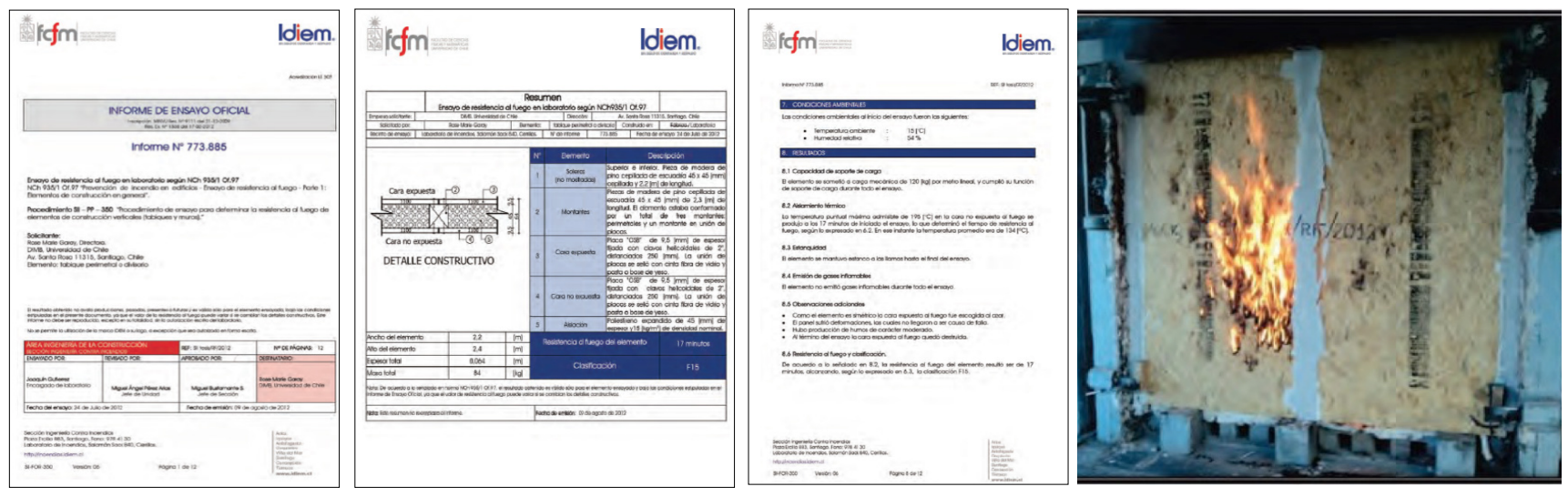

Figura 6. Muestras de los resultados de las evaluaciones resistencia al fuego Fuente: Autores, 2018

3. Verificación Térmica. La Figura 7 enseña algunas muestras de los resultados de las pruebas de confort térmico para las viviendas. Para este ejemplo, fabricada con Paneles SIP.
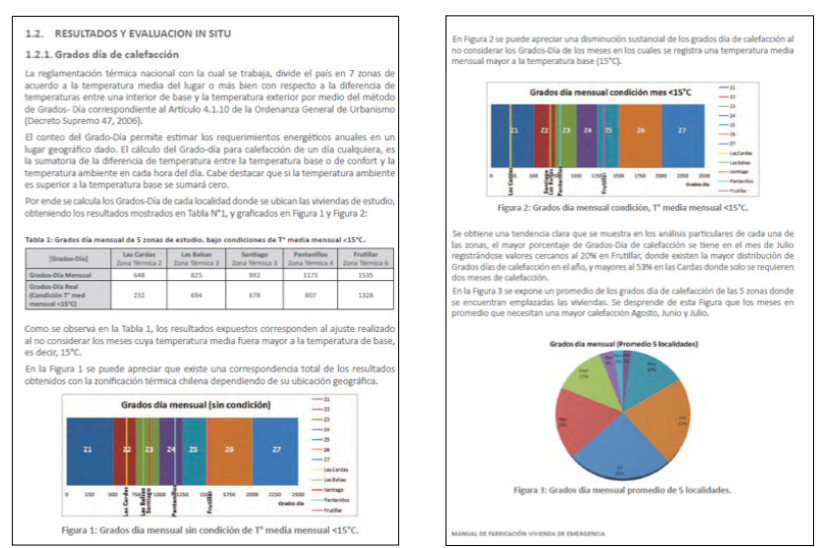

Figura 7. Muestras de los resultados de evaluaciones de confort térmico Fuente: Autores, 2018 
4. Verificación Acústica. La Figura 8 contiene muestras de los resultados de las evaluaciones acústica de la vivienda, para este ejemplo fabricada con Paneles SIP.
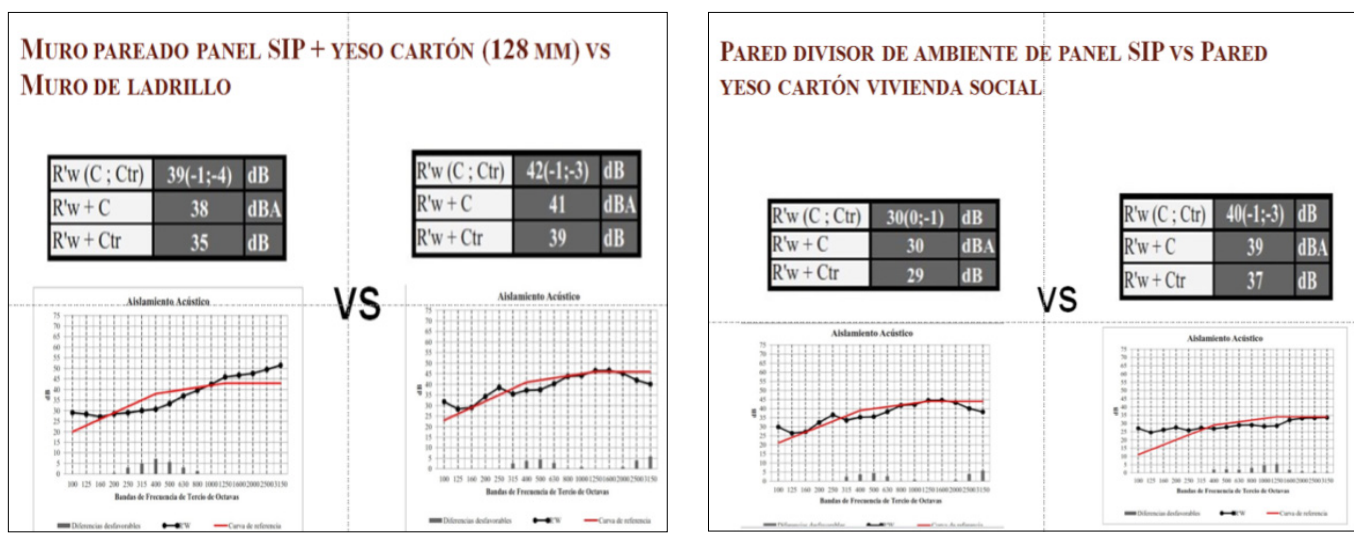

Figura 8. Muestras de los resultados de evaluaciones de confort acústico Fuente: Autores, 2018

La Tabla 9 resume la Densidad de Carga Combustible Media y Puntual Máxima para la Vivienda.

\begin{tabular}{lll} 
Sector & $\begin{array}{l}\text { Densidad de carga combustible } \\
\text { media }\left(\mathrm{mj} / \mathrm{m}^{2}\right)\end{array}$ & $\begin{array}{l}\text { Densidad de carga combustible } \\
\text { puntual máxima }\left(\mathrm{mj} / \mathrm{m}^{2}\right)\end{array}$ \\
\hline Compartimiento & 488 & 278.411 \\
\hline
\end{tabular}

Tabla 9. Resumen comparativo de carga combustible calculada $/ \mathrm{m}^{2}$ Fuente: Autores, 2018

\section{Matriz Multicriterio}

En base a un análisis multicriterio (Tabla 10) se crea una matriz con las ponderaciones de cada factor (es decir, los pesos de cada uno), esto permite tener una Jerarquización de Factores por medio de comparación por pares de Satty. Y una razón de consistencia de 0,06, que es aceptable.

\begin{tabular}{l|l|l|l|} 
Criterios Resistencia al Fuego & $\begin{array}{l}\text { Normativa } \\
\text { Vigente NV }\end{array}$ & $\begin{array}{l}\text { Actualización } \\
\text { Normativa AN }\end{array}$ & $\begin{array}{l}\text { Código de Construcción } \\
\text { Sustentables CCS }\end{array}$ \\
\hline mativa vigente NV & 1 & $1 / 3$ & 0,125 \\
\hline alización Normativa AN & 3 & 1 & $1 / 6$ \\
\hline go de Construcción Sustentables CCS & 8 & 6 & 1
\end{tabular}

RC 0,063 se acepta

Tabla 10. Matriz de jerarquización de factores

Fuente: Autores, 2018

Factores de ponderación por criterio y normalizados para cada variable incluida:

$\begin{array}{ll}0,7741935 & 0,2580645 \\ 0,8181818 & 0,2727273 \\ 0,6666667 & 0,2222222\end{array}$

Se crea un Índice Integrado de Seguridad y Sustentabilidad (IISS) empleando ponderadores para los subcriterios, lo que implica el potenciamiento económico de la madera bajo estándares medibles:

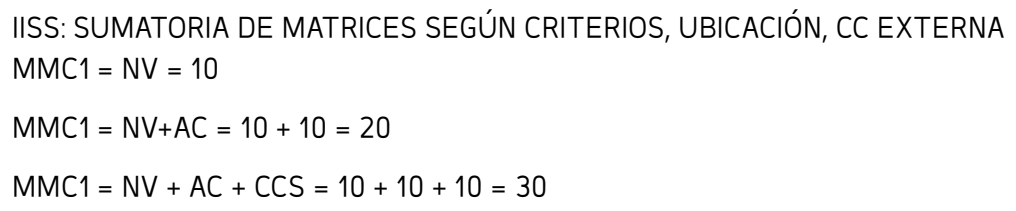




\section{Como Ejemplo:}

MMC1 representa la evaluación de una vivienda social unitaria.

MMC2 representa la evaluación de la ubicación y del entorno inmediato de una vivienda social unitaria (incluye factores como factor de riesgo por área de emplazamiento, carga combustible por biomasa u otros).

MMC3 representa un conjunto de viviendas que incorporan recomendaciones de los CCS: instalaciones eléctricas certificadas, productos menos combustibles y de baja toxicidad como preservantes y pinturas amigables con el ambiente (base agua), edificio construido en madera, pero cumpliendo estándares internacionales de seguridad, entre otros aspectos que favorecen a toda la comunidad en su conjunto.

\section{CONCLUSIONES}

Este trabajo, más allá de la entrega de datos puntuales, pretendió crear elementos nuevos de validación de la madera puesta en servicio, mediante la evaluación y estandarización de los elementos constructivos a través del IISS, con ello la industria de la construcción podrá emplear un material homogéneo, cuyas características son conocidas y valoradas por el mercado.

Aporta el IISS para la agenda de construcción sustentable: soluciones habitacionales medibles de mejor calidad, más eficientes, que otorguen mayor confort y calidad de vida a las familias que las habiten.

Contribuye a aumentar la productividad del sector: mediante criterios de sustentabilidad medibles: (disponibilidad + calidad + costos): ello implica superar brechas normativas; romper prejuicios; incorporar tecnología, así como incorporación de estandarización.

Permite productores informados de las necesidades: Dar a conocer los requisitos que deben ser satisfechos por los proveedores de manera que se acerquen a satisfacer necesidad en el encadenamiento productivo.

Los resultados también sugieren avanzar en el control de la calidad de los materiales de construcción en general y en particular para la vivienda, a través de la certificación al momento de salir de su fabricación.

En cuanto a debilidades del estudio, éste no analiza los defectos que hayan podido aparecer en el proceso constructivo y que puedan incidir en el surgimiento de nudos críticos que afecten la calidad final de las edificaciones ante el peligro de incendios. En segundo lugar, faltaría evaluar el comportamiento de las viviendas con sus ocupantes en ella tomando en cuenta el factor temporal.

En tercer lugar, faltaría aplicar los índices creados, en situaciones efectivas y en terreno, para comprobar su validez y confianza.

En general, en los sectores populares no solo de Chile sino que también de América Latina, sus viviendas son más bien evolutivas (Tapia \& Mesías, 2001), es decir, aquellas se están constantemente transformando. Esa cualidad de transformación conlleva sucesivos y versátiles sistemas constructivos y variedad de calidades ejecutadas por sus usuarios o propietarios que alteran un patrón inicial de calidad predeterminado. En estos procesos, una vivienda de buena habitabilidad puede bajar en su umbral de atributos por las razones expuestas. Por estos motivos, la propuesta de índices sugeridos puede tener dificultades de factibilidad en su aplicación práctica si los estándares de superficie inicial de las viviendas no responden a las expectativas de quienes las habitarán. Posiblemente aplicaría de mejor modo como tipología para una vivienda de uso temporal como podría ser una para responder a emergencias por desastres.

Finalmente, el índice puede ser un primer avance para el mejoramiento de estándares contra incendios, sin descuidar los otros factores componentes de la habitabilidad los cuales en conjunto, son constitutivos del bienestar habitacional.

\section{REFERENCIAS}

Arteaga, C. \& Tapia R. (2015). Vulnerabilidades y Desastres Socio-Naturales. Experiencias Recientes en Chile. Santiago de Chile: Editorial Universitaria, Colección: Estudios.

Corporación Chilena de la Madera CORMA. ( 2007). Centro de Transferencia Tecnológica de la Madera de la Corporación Chilena de la Madera. Manual de Construcción de Viviendas de Madera. Unidad 15: Protección Contra El Fuego. Santiago de Chile: CORAMA, pp. 375-397. 
Campos, L. \& Medic, A. (2014). Hábitat Residencial: Instrucciones de uso. entrega el marco general de la reflexión sobre el hábitat residencial. Santiago de Chile: INVI-FAU, Universidad de Chile.

Cutter, S., Barnes, L., Berry, M; Burton, C., Evans, E., Tate, E. \& Webb, J. (2008). A place-based model for understanding community resilience to natural disasters. Global Environmental Change, 18(4), pp. 598-6o6. DOI: https://doi.org/10.1016/j.gloenvcha.2008.07.013

Eastman, J. R., Kyem, P. A., Toledano, J. \& Jin, W. (1993). GIS and decision Making. Ginebra: United Nations Institute for Training and Research UNITAR.

Garay, R. M., Pfenniger F., Tapia, R., \& Larenas, J. (2014). Desarrollo de bases técnicas y normativas para prototipos de vivienda modular, con énfasis en soluciones de emergencia, bajo criterios técnicos, geográficos y económicos que mejoren su eficiencia y funcionalidad [Proyecto FONDEF DO9I1058]. Santiago de Chile: INVI-FAU Universidad de Chile. Disponible en: http://www.forestal.uchile.cl// investigacion/proyectos/114518/proyecto-fondef- dogi1058 (revisado el 17 julio de 2018)

Garay, M. \& Silva, R. (2011). Comportamiento de tableros a base de madera, durante ensayos de atenuación ultrasónica. Revista de la Construcción, 10(3), pp.41-51.

Garay, R. (2016, Diciembre). La problemática de la protección contra el fuego en la construcción de viviendas y su relación con otros criterios técnicos. Aceptado para el V Congreso Red Iberoamericana de protección de la madera, Colonia, Uruguay.

ReportLinker. (2018). Global Wood Industries: Report summary. Lyon: ReportLinker. Disponible en: https://www.reportlinker.com/report-summary/Wood/1765o/Global-Wood-Industry.html (revisado el 20 junio de 2018)

Gómez, M. \& Barredo, J. (2005). Sistemas de Información Geográfica y evaluación multicriterio en la ordenación del territorio, 2da. Ed. México: RA-MA Editorial.

Hernández, J. (2008). Recopilación de información sobre comportamiento al fuego de elementos de construcción de viviendas [Tesis de Pregrado]. Santiago de Chile: Universidad de Chile.

Hildebrandt J., Hagemann N. \& Thrän D. (2017). Contribution of wood-based construction materials for leveraging a low carbon building sector in Europe. Sustainable Cities and Society, 34, pp.405- 418. DOI: http://dx.doi.org/10.1016/j.scs.2017.06.013

Instituto Forestal de Chile INFOR. (2016). Industria Forestal Primaria en Chile, Período 2005-2016. Santiago de Chile: INFOR.

Instituto Nacional de Normalización Chile INN. (1985). Prevención de incendio en edificios - Ensayo de reacción al fuego - Parte 2: Determinación del calor de combustión de materiales en general. NCh1914/2. Santiago de Chile: INN.

Instituto Nacional de Normalización Chile INN. (1998). Prevención de incendio en edificios Clasificación de los edificios según su densidad de carga combustible media y densidad de carga combustible puntual máxima. NCh1993 Of.98. Santiago de Chile: INN.

Instituto Nacional de Normalización Chile INN. (1990). Prevención de incendios en edificiosDeterminación de cargas de combustibles. NCh1916 Of.1999. Santiago de Chile: INN.

Janssen, R. \& Rietveld, P. (1990). Multicriteria Analysis and GIS: An Application to Agricultural Landuse in The Nederlands. En Scholten, H. \& Stillwell, J. (Eds.), Geographical Information Systems for Urban and Regional Planning. Dordrecht: Kluwer.

Jirón M. P., Toro B. A., Caquimbo S. S., Goldsack, L. \& Martínez M. L. (2004). Bienestar habitacional: guía de diseño para un hábitat residencial sustentable. Santiago de Chile: INVI-FAU Universidad de Chile, Universidad Federico Santa María \& Fundación Chile. Disponible en: http://libros.uchile. cl/664 (revisado el 17 Julio de 2018)

Macari, R. (2015). Criterios que determinan los requerimientos de resistencia al fuego de elementos estructurales [Tesis de Pregrado]. Santiago de Chile: Universidad de Chile.

Ministerio de Vivienda y Urbanismo MINVU. (2014). Listado oficial de comportamiento al fuego de elementos y componentes de la construcción. Santiago de Chile: MINVU. Disponible en: http://www. minvu.cl/incjs/download.aspx?glb_cod_nodo $\backslash$ x3d20070606164405 $\backslash$ x26hdd_nom_archivo $\backslash$ x3dListado\%2oOficial\%2ode\%2oComportamiento\%2oal\%2oFuego\%2oE14-1_2014.pdf (revisado el 17 Julio de 2018)

Ministerio de Vivienda y Urbanismo MINVU. (2009). Ordenanza General de Urbanismo y Construcciones, OGUC, Titulo 4: De la Arquitectura. Capítulo 3: De las Condiciones de Seguridad Contra Incendio. Santiago de Chile: MINVU. 
Loyola, M. \& Goldsack, L. (2010). Constructividad y Arquitectura. Santiago de Chile: FAU Universidad de Chile.

Lignum. (2017). Nuevas soluciones constructivas se incorporan a los listados oficiales del MINVU. Santiago de Chile: Lignum. Disponible en: http://www.lignum.cl/2017/12/o7/nuevas-soluciones-constructivas-madera-se-incorporan-los-listados-oficiales-del-minvu/ (revisado el 17 Julio de 2018)

Luhmann, N. (1998). Sociología del Riesgo. Ciuedad de México: Editorial Triana.

Max-Neef, M., Elizalde, A. \& Hopenhayn, M. (1986). Desarrollo a Escala Humana. Una opción para el futuro. Santiago de Chile: CEPAUR.

Naciones Unidas UN. (2010). Diagnóstico de la situación de la Reducción de Riesgos de Desastres en Chile. Santiago de Chile: UNISDR.

National Fire Protection Association NFPA. (2013). Community Wildfire Safety Through Regulation. Quincy, E.E.U.U.: NFPA. Disponible en: https://www.nfpa.org/-/media/Files/Public-Education/Bytopic/Wildland/WildfireBestPracticesGuide.ashx?la=en (revisado el 17 Julio de 2018)

Registro CDT. (2018). Fichas técnicas de materiales de Construcción. Registro CDT. Santiago de Chile. Disponible en: http://www.registrocdt.cl/registrocdt/www/adminTools/fichasDeProductos.aspx (revisado el 17 Julio de 2018)

Saaty, T. (1980). The analytical hierarchy process. New York: McGraw Hill.

Skullestad J., Bohne R. \& Lohne J. (2016). High-Rise Timber Buildings as a Climate Change Mitigation Measure - A Comparative LCA of Structural System Alternatives. Energy Procedia, 96, pp.112-123.

Tapia, R. \& Mesías, R. (2002). Hábitat Popular Progresivo. Vivienda y Urbanización. Programa de Ciencia y Tecnología para el Desarrollo CYTED. Santiago de Chile: CYTED.

Toro, A., Jirón, P. \& Goldsack, L. (2003). Análisis e incorporación de factores de calidad habitacional en el diseño de las viviendas sociales en Chile. Propuesta metodológica para un enfoque integral de la calidad residencial. Revista INVI, 18 (46), pp.9-21.

Velásquez, M. \& Cristóbal, J. (2010). Diseño de los elementos constructivos de una vivienda de madera unifamiliar aislada según requerimientos mínimos de resistencia al fuego [Tesis de Pregrado]. Valdivia, Chile: , Escuela de Construcción Civil, Universidad Austral de Chile.

Voogd, H. (1983). Multicriteria Evaluation for Urban and Regional Planning. London: Pion. 